\title{
“O ENFERMEIRO” DE MACHADO DE ASSIS: \\ UM EMBATE ENTRE A ESSÊNCIA E A APARÊNCIA EM CONVERSAS COM A PSICOLOGIA
}

\author{
Virginia Silveira Baldow* \\ Roberta Bolzan Jauris ${ }^{* *}$ \\ Fabiana Andrade Santos ***
}

RESUMO: Este estudo objetiva apresentar uma análise interdisciplinar do conto "O Enfermeiro" de Machado de Assis, ancorada nas áreas da Literatura e da Psicologia. Esboçamos uma reflexão sobre o supracitado gênero, analisando o modo como o autor concebe o comportamento humano, evidenciado pelo narrador-personagem. Nessa perspectiva, elaboramos uma releitura de "O Enfermeiro", em cotejo com "O almocreve"- capítulo XXI de Memórias póstumas de Brás Cubas/ Machado de Assis-, por considerarmos intrínseca a relação de sentido subjacente aos fatos narrados. Observamos, assim, o tom irônico de que os narradores se utilizam, em ambos os casos, para atrair a cumplicidade do leitor. O percurso teórico que fundamenta esta investigação se embasa, principalmente, nas postulações de Bosi (1982; 2007), Fischer (1998), Souza (1998) os quais refletem acerca da obra contística machadiana e também em Dalgalarrondo (2008) e Santos (2009) pesquisadores na área da Psicologia.

PALAVRAS-CHAVE: Comportamento humano; Machado de Assis; Narrador.

\footnotetext{
* Professora Assistente da Universidade Estadual do Sudoeste da Bahia (Uesb). Mestre em Literatura e Diversidade Cultural pela Universidade Estadual de Feira de Santana (Uefs).

** Professora da Universidade Estadual do Sudoeste da Bahia (Uesb). Mestre em Educação e Contemporaneidade pela Universidade do Estado da Bahia (PPGEduC-Uneb).

*** Professora Assistente da Universidade Estadual do Sudoeste da Bahia (Uesb). Mestre em Letras e Linguística pela Universidade Federal da Bahia (Ufba).
} 


\section{Introdução}

Intenta-se com esta reflexão apresentar uma análise interdisciplinar do Conto "O Enfermeiro" de Machado de Assis, procedendo a uma interface entre as áreas de Psicologia e Literatura. Tal interação é por demais oportuna, porquanto nos debruçamos a escrutinar o comportamento do narrador-personagem do supracitado gênero, expresso, não apenas no diálogo que ele mantém com o seu interlocutor-imaginário, mas na captação da sua "crise" de consciência e na sua justificativa para o seu comportamento.

Na primeira seção, esboçamos algumas considerações de Bosi (1982) e outros expoentes da Literatura acerca da temática dos contos machadianos, ponderando sobre o comportamento de Procópio - narrador- personagem de "O Enfermeiro"-, numa abordagem interdisciplinar com a Psicologia.

A seção intitulada “O enfermeiro e o almocreve: uma análise transtextual” apresenta uma releitura do supracitado conto em cotejo com "O almocreve" - capítulo XXI do romance Memórias póstumas de Brás Cubas/Machado de Assis. Nas duas narrativas, ponderamos não apenas a semelhança de atitudes entre Procópio e Brás Cubas, mas o tom irônico machadiano, manifestado pelos dois narradores-personagens que, ao tentarem atrair a cumplicidade do interlocutor imaginário, demonstram aspectos comportamentais característicos do ser humano no enfrentamento de determinadas situações.

Nas considerações finais, avaliamos que, nas referidas obras machadianas, o autor revela que a natureza humana se reflete por meio da alteridade que nos conduz a rechaçar comportamentos, intrínsecos do nosso ser, e ainda "desconhecidos" pelo nosso consciente.

\section{Incursões teóricas por meio de uma análise interdisciplinar}

Segundo Bosi (1982), uma característica visível nos contos de Machado de Assis, especialmente nos da segunda fase ${ }^{1}$, é a contradição entre parecer e ser. O crítico vê em

\footnotetext{
${ }^{1}$ Nesta fase, segundo Bosi (1982), encontram-se os contos escritos após a publicação de Memórias Póstumas de Brás Cubas, a obra de Machado seria, então, constituída de duas fases.
} 
suas narrativas a suspeita de que "a aparência funciona como a essência", "não só na vida pública, mas no segredo da alma" (BOSI, 1982, p. 441). O tom pessimista de Machado acerca da alma humana é uma característica que marca a maior parte dos seus contos. Há nesse "segundo Machado" uma sensível inclinação para os lados obscuros da humanidade e, assim, sua obra contística é constituída por temas e personagens, envolvidos numa atmosfera, em que predominam o mal e o lado corrompido do homem o qual se guia por seus instintos egoístas. Tais instintos dominam o interior das personagens e determinam suas ações.

Essas questões são claramente perceptíveis no conto "O enfermeiro", que fornece pistas ao leitor sobre a maneira como o escritor concebe o homem e a sociedade. É possível, então, classificá-lo como um conto psicológico, por se tratar, também, de uma leitura da interioridade humana. Por essa interioridade humana, Dalgalarrondo (2008) entende que os pensamentos humanos são constituídos por conceito, juízo e raciocínio, os quais movimentam a vida do sujeito que, ao enfrentar determinadas situações de conflitos pessoais, recorre à sua consciência repleta de moral e ética, moldada pela sua formação e cultura.

Referindo-se aos contos machadianos, em artigo intitulado "Contos de Machado: da ética à estética”, Luís Augusto Fischer (1998) divide-os em dois polos: contos éticos e contos estéticos. Sobre o primeiro, o autor esclarece:

[...](a) não apresenta narrador relevante para a consecução do efeito literário, antes funcionando como mera voz ou mero ponto de partida da enunciação, cuja função é por de pé o relato, sem intervenção no curso do enredo; (b) não apresenta qualquer personagem forte, tomado o termo no sentido constitutivo da narração, e ao contrário apresenta "personagens" que não passam de ventríloquos, de títeres, eventualmente de tipos ou caricaturas, que atuam ao sabor de um valor narrativo maior; e (c) apresenta-se sob a roupagem de uma forma já consagrada (FISCHER, 1998, p. 158-159; apud Aquino, 2005).

Nesse primeiro polo, a figura do narrador se manifesta, discretamente, construindo o cenário e as ações sem intervenções significativas (FISCHER, 1998). Aqui se situam os 
contos conhecidos como morais ou contos-teorias (BOSI, 2007), cuja voz narrativa não é tão nítida em relação aos contos do segundo polo que assim se identificam:

[...] (a) apresenta um narrador absolutamente relevante para a consecução do efeito literário, um narrador intruso, intrusíssimo, sem o qual o mesmo conto deixa de ser como é, um narrador que chama a atenção sobre elementos do enredo e sobre si mesmo, ajuizando, filosofando, comparando, enfatizando, convocando o leitor, jogando-lhe em rosto sua precariedade etc.; (b) apresenta personagens fortes, no sentido estrutural, que são outra coisa que títeres, porque tem psicologia, intensidade, força expressiva, numa palavra, vida; (c) apresenta forma inventiva, não convencionada, não consagrada, mas, pelo contrário, especulativa, que vai da descrição crua ao delírio, da sequência de eventos no tempo à subversão da ordem temporal [...] (FISCHER, 1998, p. 158,59).

Inserem-se, no segundo polo, os contos ditos psicológicos (AQUINO, 2005), nos quais o narrador se impõe, intervindo de forma determinante no fato narrado, o que parece acontecer no conto a que nos propomos analisar.

\section{Evidências de um narrador perspicaz}

Narrado pelo protagonista Procópio, o conto se apresenta com uma advertência do narrador-personagem, ao interlocutor imaginário, alertando-o quanto a não divulgação do que lhe será confidenciado até que aquele morra, porquanto, desenganado está, segundo ele, a poucos dias de sua morte:

Parece-lhe que o que se deu comigo em 1860, pode entrar numa página de livro? Vá que seja com a condição única de que não há de divulgar nada antes da minha morte. Não esperará muito, pode ser que oito dias, se não for menos; estou desenganado (ASSIS, 2008, p. 355).

Trata-se da narrativa de um episódio ocorrido com o protagonista, então homem pobre, copista de textos teológicos a serviço de uma paróquia dirigida por um vigário, antigo colega de escola de quem recebia “casa, cama e mesa” (ASSIS, 2008, p. 357), em troca 
do que fazia. Foi este vigário que, vendo em Procópio os atributos de uma pessoa "entendida, discreta e paciente" (ASSIS, 2008, p. 357), encaminhou-o, por solicitação de outro padre, a uma vila do interior onde serviria de enfermeiro ("mediante um bom ordenado") para um velho, Coronel Felisberto, conhecido na vila por sua fama de "insuportável, estúrdio exigente" (ASSIS, 2008, p. 358). "O velho gastava mais enfermeiro que remédios", diz o protagonista.

Após a primeira semana que se deu de forma tranquila entre os dois, Procópio passa a sofrer os maus tratos impetuosos do coronel, os quais se tornavam cada vez mais constantes e violentos. $\mathrm{O}$ último desses ataques resultou numa tragédia: Procópio, ao sentir bater-lhe uma moringa na face esquerda, arremessada por Felisberto, esgana-o a ponto de matá-lo. A partir de então, um sentimento de remorso, ao que parece, mais de medo, ao pensar na possibilidade de ser preso, passa a dominar a mente do enfermeiro: "Só então posso dizer que pensei claramente no castigo. Achei-me com um crime às costas e vi a punição certa. Aqui o temor complicou o remorso" (ASSIS, 2008, p. 361).

Os sentimentos que envolvem Procópio perpassam a linha da moral e da ética, no entrecruzamento entre o consciente e o inconsciente humano, reverberado sobre o julgo entre o que se deve e o que se deseja fazer. Nesse conflito, Procópio enfrenta, durante o seu exercício de enfermeiro, um dilema em que, de um lado, encontram-se seus sentimentos iniciais de autoconceitos, denominando-se "idiota", "burro", "moleirão", ao sofrer de isolamento e ansiedade pelo desejo de sair do papel de cuidador do coronel (um sujeito violento que lhe acometia, internamente, ódio e aversão) e, de outro, a piedade e seu senso de justiça, envoltos por suas crenças e valores que o mantinham na função. Esse senso lhe apavora, provocando delírios, identificados na Psicologia como "juízos patologicamente falsos" [...] "é um erro do ajuizar" (DALGALARRONDO, 2008, p. 209), que se agrava, em Procópio, num contraponto com sua consciência que o julga assassino, quando do óbito do Sr. Felisberto, provocando alucinações desencadeadoras da melancolia. Com isso, busca alternativas para justificar suas ações perante as situações que vão se desvelando, no decorrer da narrativa, antes e após a morte do coronel. 
Essa mistura de sentimentos se intensifica quando Procópio recebe a notícia de que fora constituído, pelo coronel, seu herdeiro universal. Inicialmente, pensa em doar todos os bens que receberia. Mas, à medida que se vê diante de tamanha riqueza, tenta encontrar razões que justifiquem o ato de violência. Assim, os elogios que recebia das pessoas da vila pelo cuidado dispensado a um velho tão ruim, as lembranças dos maus tratos aliados à forte probabilidade da morte do velho (já estava tão debilitado), trouxeram-lhe afago e alívio para a sua consciência adoecida pelo assassinato.

É exatamente isso que nos chama a atenção. A postura do narrador que Machado apresenta nesta narrativa; um narrador que

[...] se compraz na mobilidade pura, assumindo todo gênero de caracteres, desempenhando os papéis mais diversos, articulando uma alternância sistemática de perspectivas, modulando vários pontos de vista sempre recusando a possibilidade de se imobilizar na representação doutrinária de um só papel, na adoção monológica de um ponto de vista pretensamente normativo. (SOUZA, 1998, p. 65)

A todo instante, o narrador, móvel, absorto em conflitos, busca envolver o leitor nesse universo duplo, ambíguo, como que procurando condescendência pelos seus sentimentos. Dessa forma, o leitor é sutilmente atraído para dentro do texto e, já envolvido nesse âmbito conflituoso, o narrador persuade-o, suscitando dúvidas sobre a morte do velho “insuportável”. É o que parece evidenciar os trechos de alguns discursos do narrador, dirigindo-se ao leitor:

\begin{abstract}
"Imagine o meu pasmo"; (...) "Crime ou luta?" (...) "E quem sabe mesmo se a luta e a morte não foram apenas coincidentes? Poderia ser, ora até o mais provável; não foi outra coisa. (...)" "e referiamme casos duros, ações perversas, algumas extraordinárias. Quer que lhe diga?"...) Pode ser que eu, involuntariamente, exagerasse a descrição que então lhes fiz; mas a verdade é que ele deveria morrer, ainda que não fosse daquela fatalidade..." (ASSIS, 2008, p. $362,363.364 / 365)$
\end{abstract}

Sob este propósito Bosi (1982) assegura: 
Começa aqui, mediante perguntas, reticências e dúvidas, a sinuosa justificação do ato. A consciência de Procópio vai buscando e encontrando atenuantes sucessivos à medida que o antigo enfermeiro se aproxima da herança universal do coronel. (BOSI, 1982, p. 190)

Nesse ínterim, o leitor se torna um coparticipante do texto, tentando completar-lhe o sentido. Seria Procópio realmente culpado? Não teria sido coincidência a morte natural do coronel com o fato ocorrido? A caracterização detalhada e aparentemente casual do enredo registra um narrador perspicaz como que sempre esperando que o leitor complete as lacunas construídas, ardilosamente, no fato narrado. Porém, o que nos parece mais importante no conto em questão, não é saber se, de fato, houve ou não um crime, se Procópio matou ou não Felisberto, mas sim repensar, dentre uma infinidade de possibilidades de leitura e atualizações do conto em estudo, pelo menos dois aspectos relacionados à alma humana apresentados por Machado.

O primeiro deles nos faz ver que o ser humano, dominado por impulsos (nesse caso um acesso de fúria) e "dotado de um poder absoluto, age de forma extremamente violenta contra o seu semelhante" (ZILBERMAN, 2008, p. 513), podendo chegar às últimas consequências, como o assassinato. É o que observamos na seguinte passagem: "Não tive tempo de desviar-me; a moringa bateu-me na face esquerda e tal foi a dor que não vi mais nada; atirei-me ao doente, pus-lhe as mãos ao pescoço, lutamos e esganei-o” (ASSIS, 2008, p. 360). Tal episódio evidencia a relatividade do ser e explora o problema dos limites da razão. Procópio, um homem sóbrio, calmo "pessoa entendida, discreta e paciente" (ASSIS, 2008, p. 357), como se dá a entender na leitura, por um acesso de fúria, num breve momento, age exatamente igual a alguém que nunca conhecera as virtudes da sobriedade e paciência.

O segundo aspecto apresentado por Machado está no fato de que, tratando-se da alma humana, quando em conflito que o requeira, a aparência sobrepuja a essência. Tal embate se manifesta, especialmente, a partir dos primeiros instantes que sucederam à morte do coronel, estendendo-se até o final da narrativa. Inicialmente, Procópio tenta esconder a culpa que o consumia, 
Vi no pescoço o sinal das minhas unhas; abotoei alto a camisa e cheguei ao queixo a ponta do lençol. Em seguida chamei um escravo, disse-lhe que o coronel amanhecera morto; mandei recado ao vigário e ao médico. (ASSIS, 2008, p. 362)

Desde então, o protagonista não saiu da "sala mortuária", "tinha medo de que descobrissem alguma coisa" (ASSIS, 2008, p. 362). As suas atitudes, durante o velório, bem como a expressão de conflito que estampava em seu rosto, conferiam-lhe, perante as pessoas que ali estavam, a crença de que toda aquela aflição se devia ao pesar pela morte daquele senhor e não ao remorso e ao medo de que descobrissem a verdade:

Vindo a hora, fechei o caixão, com as mãos trêmulas, tão trêmulas que uma pessoa que reparou nelas, disse a outra com piedade: Coitado do Procópio! Apesar do que padeceu, está muito sentido. (ASSIS, 2008, p. 362)

Nesse trecho, notamos que o enfermeiro, tirando proveito dos comentários, veste uma máscara de benfeitor. E mais uma vez, ele ratifica essa impressão: “[...] Quando tudo acabou respirei. Estava em paz com os homens. Não o estava com minha consciência [...]" (ASSIS, 2008, p. 362). Em várias situações, o narrador enfatiza que os outros acreditavam que ele estava sofrendo a morte do velho coronel, fato esse que, de certa forma, aliviava-o, mesmo que não estivesse em paz consigo mesmo. O mais importante é que, diante da sociedade, ele continuava a ser um bom homem, aquele que cuidou do coronel, até o fim.

Santos (2009, p. 35), em seus estudos acerca das ações humanas, analisa o medo que temos do "mal de ser", “da desumanização do sentido”, trazendo uma revelação impactante, ao apresentar uma existência humana contraditória, em relação ao que se concebe como a real humanidade do homem, caracterizada por uma repulsa ao seu próprio ser. Relacionando essa reflexão a Procópio, observamos o medo que ele tem da sua própria humanidade, ao buscar explicações sociais para seu feito. Esse comportamento revela que o homem se guia por crivos sociais e passa a se aceitar, ou não, perante olhares dos outros; 
pois, mesmo inconscientemente, a cultura de que fazemos parte nos constitui e direciona nossos modos de vida, em uma luta permanente entre a aparência e a essência.

Quando da notícia de que seria o herdeiro universal de Felisberto, notamos lenta e sutilmente a maneira gradativa como a aparência e a essência vão se amalgamando a ponto de acalentar a consciência do então criminoso:

Cogitei em recusar a herança [...] pensei nisso três dias [...] receberia a herança e dá-la-ia toda [...] era também o modo de resgatar o crime por um ato de virtude [...] A imaginação ia reproduzindo as palavras, os gestos, toda a noite horrenda do crime [...]. (ASSIS, 2008, p. 363)

Diante dessas reflexões, o narrador-personagem busca justificar o seu ato e convencer-se de que fora uma fatalidade: "O coronel não podia viver muito mais; estava por pouco, [...] Já não era vida, era um molambo de vida” (ASSIS, 2008, p. 364). Aqui, o leitor é induzido à suspeita de que Procópio fizera um favor ao coronel, tirando-lhe a vida. Deveria mesmo rejeitar a herança? À medida que o enfermeiro se aproximava do patrimônio, observamos que a consciência moral passa a ser modelada pelo interesse pessoal, diante da possibilidade do ganho, do lucro e do prestígio. É isso que Machado procura mostrar, ironicamente, na passagem a seguir:

Entrando na posse da herança, converti-a em títulos e dinheiro. Eram então passados muitos meses, e a ideia de distribuí-la toda em esmolas e donativos pios não me dominou como da primeira vez; achei mesmo que era afetação. Restringi o plano primitivo: distribuí alguma coisa aos pobres, dei à matriz da vila uns paramentos novos, fiz uma esmola à Santa Casa da Misericórdia, etc.: ao todo trinta e dois contos. Mandei também levantar um túmulo ao coronel, todo de mármore [...]. Os anos foram andando, a memória tornou-se cinzenta e desmaiada. Penso às vezes no coronel, mas sem os terrores dos primeiros dias. (ASSIS, 2008, p. 364)

Sob este propósito, é interessante ressaltar também que a escolha do nome "Procópio", feita por Machado, não foi aleatória: Procópio - "aquele que ganha". O narrador /protagonista, portanto, faz jus ao significado do seu nome. 


\section{O enfermeiro e o almocreve: uma análise transtextual}

Em face do olhar fixo na personalidade humana, é oportuno aqui ressaltar o entrecruzamento de "O enfermeiro" com o capítulo XXI de Memórias póstumas de Brás Cubas, intitulado "O almocreve", em que o narrador, também personagem, relata um acidente que lhe aconteceu quando o jumento que o levava empacou, arremessando-o fora da sela. $\mathrm{O}$ personagem com o pé esquerdo, preso no estribo, seria arrastado pelo animal enfurecido, pronto a disparar (chegou a dar dois saltos) não fosse um almocreve que prontamente detivera o jumento. Enfim, a vida de Brás Cubas fora poupada, graças à ação do almocreve. Envolto num sentimento de gratidão, o narrador pensou em dar-lhe três das cinco moedas de ouro que trazia consigo, em retribuição ao gesto do pobre homem. Mas, transcorridos alguns instantes, das três moedas, pensou em dar-lhe duas... uma..., até que lhe entregou apenas uma moeda de prata e não de ouro, como pretendia no ímpeto do ocorrido. Ainda assim, o beneficiado se arrependeu de ter doado a moeda de prata, pensando que alguns poucos vinténs seriam suficientes para o contentamento daquele "pobre-diabo, que nunca jamais vira uma moeda de ouro" (ASSIS, 1982, p. 221).

Observando as duas narrativas, parece inevitável considerar a relação análoga de uma com a outra, já que os dois narradores apresentam o mesmo sentimento, em situações diferentes, que se constitui como um espelho da conduta dúbia do ser humano. Nesse caso, o diálogo entre os textos se dá num exercício da transtextualidade, ou seja, “[...] Transtextualidade, ou transcendência textual do texto, é tudo o que se coloca em relação manifesta ou secreta com outros textos (GENETTE, 2006, p. 7). Nas narrativas em cotejo, o elemento fundamental caracterizador da transtextualidade está no acesso à informação de ma- 
neira não linear em que ocorrem fortes analogias que se realizam no eixo das relações paradigmáticas $^{2}$, isto é, na verticalidade da realização da linguagem, não se limitando, portanto, às relações sintagmáticas ${ }^{3}$, as quais são estabelecidas numa cadeia essencialmente linear.

Dessa forma, o conto "O enfermeiro" remete à ideia contida em "O almocreve", evocando, na mente do leitor atento, a mesma ironia sentida no capítulo mencionado. Assim, é importante ressaltar que essa atualização de um texto no outro não se manifesta claramente na superfície do enunciado do conto, por isso, conforme afirmamos, é uma manifestação não linear, que ocorre sutilmente, nas entrelinhas, sem qualquer referência explícita na superfície textual.

Tanto num como noutro caso, observamos um narrador que personifica os múltiplos papeis correspondentes à "diversidade qualitativa da atuação histórico-social dos homens” (SOUZA, 1998, p. 67). Tal personificação se esboça através da ironia. Segundo Brayner (1979):

A força da ironia jaz no antigo e sempre atual prazer humano em fazer contrastar a Aparência com a Realidade, isto é, no conflito de dois significados dentro de uma estrutura dramática peculiar. De início, um significado - a aparência - apresenta-se como verdadeiro; entretanto, o aprofundamento contextual deste nível faz gradativamente um outro lado da moeda - a realidade - diante da qual o primitivo significado surge como falso e limitado, sendo essencial a percepção desta duplicidade fundamental para a compreensão de qualquer ironia.[...] Pode-se dizer que a ironia se estabelece na inadequação voluntária de um significante com seu significado (BRAYNER, 1979, p. 100).

\footnotetext{
${ }^{2}$ Em linguística moderna, o paradigma é constituído pelo conjunto de unidades que mantém entre si uma relação virtual de substituilidade. Em seus estudos sobre linguística, Saussure se refere às relações paradigmáticas nas mesmas situações em que se refere às "relações associativas" (DUBOIS et al.,1973).

${ }^{3}$ Enquanto a relação paradigmática associa uma unidade da língua realizada num enunciado a outras não presentes no enunciado considerado, a relação sintagmática é realizada, com certas unidades presentes no enunciado (DUBOIS et al.1973).
} 
Diante dessa análise compreendemos que é por meio da ironia que Machado faz ecoar as atitudes vacilantes do homem, movido acima de tudo por seus interesses pessoais. Ainda que em diferentes gêneros (conto e romance, respectivamente), os dois textos são construídos sob a perspectiva de evidenciar o egoísmo, as máscaras sociais, os interesses os quais são narrados, de forma subliminar e subjacentes a histórias aparentemente casuais que parecem ter outros enfoques mais simples, em sua superfície textual. Assim, em Machado, a simples contemplação do destino humano, a mera percepção do absurdo da vida resultam em ironia (SENNA, 2008), recurso utilizado amplamente nas duas narrativas e através do qual o leitor, inevitavelmente, sente-se desnudo diante da visão trágica e, ao mesmo tempo, tão real do homem.

\section{Considerações finais}

Nos enredos mencionados, é inevitável que o leitor passe por um processo de reconhecimento e identificação, se não com todas as características descritas, ao menos com algumas delas, numa atitude de autoconfrontação. Em um matiz literário, a psicologia dispõe que o pulsar de ser humano reverbera no outro e é envolto por questões morais e éticas que nos conduzem nas ações que realizamos, em constante interação com o mundo. Toda interação gera uma ação que podemos julgar perante uma visão pessoal ou coletiva, e isso pode ser feito conforme a reflexão que o homem faz de si no mundo em que vive, estando ou não preparado para enfrentar.

A leitura de tais narrativas, portanto, nos remete ao entendimento de uma das funções primordiais da Literatura, a função humanizadora de que nos fala Antonio Candido (1995) na medida em que os textos literários despertam em nós sentimentos e atitudes que nos tornam mais compreensivos, acolhedores e sensíveis ao outro. Esse processo, portanto, é por demais frutífero para o fomento do "exercício da reflexão" e quiçá de transformações pessoais. 


\title{
“THE NURSE" OF MACHADO DE ASSIS: AN EMBATING BETWEEN ESSENCE AND APPEARANCE IN CONVERSATIONS WITH PSYCHOLOGY
}

\begin{abstract}
This study aims to present an interdisciplinary analysis of the short story "O Enfermeiro" by Machado de Assis, it is based in the areas of Literature and Psychology. We did a reflection about the genre mentioned, analyzing how the author conceives human behavior, as evidenced by the narrator-character. In this perspective, we elaborated a re-reading of "O Enfermeiro", in comparison with "O almocreve" - chapter XXI of Memórias Póstumas de Brás Cubas/ Machado de Assis-, because we considered intrinsic the relation of meaning underlying the facts narrated. Therefore, we observe the ironic tone that narrators use, in both cases, to attract the complicity of the reader. The theoretical course this investigation is based mainly on the postulates of Bosi (1982, 2007), Fischer (1998), Souza (1998), which reflect about Machadiana work and in Dalgalarrondo (2008), GarciaRoza (2008) and Santos (2009) researchers in the area of Psychology.
\end{abstract}

KEYWORDS: Human behavior; Machado de Assis; Storyteller.

\section{REFERÊNCIAS}

AQUINO, Ivânia Campigotto. Poder, submissão e consciência no mundo do trabalho: uma leitura do conto machadiano "O enfermeiro". In: Revista Outros Sertões. $\mathrm{N}^{\circ}$ 2.dez/2008.Universidade do Estado da Bahia. Salvador: UNEB, 2005.

ASSIS, Machado. O enfermeiro. In: FERNANDES, Rinaldo de. Capitu Mandou Flores: Contos para Machado de Assis nos cem anos de sua morte. São Paulo: Geração Editorial, 2008 p. 357.

BRAYNER, Sonia. Labirinto do Espaço Romanesco: tradição e renovação da literatura brasileira, 1880-1920. Rio de Janeiro: Civilização Brasileira, Brasília, 1979.

BOSI, Alfredo (et al.). Antologia \&̋ Estudos: Machado de Assis. São Paulo: Ática,1982.

BOSI, Alfredo. Machado de Assis: o enigma do olhar. 4 ed. São Paulo: Martins Fontes, 2007.

CANDIDO, Antonio. Vários escritos. $3^{\mathrm{a}}$ ed. São Paulo: Livraria Duas Cidades, 1995.

DALGALARRONDO, Paulo. Psicopatologia e semiologia dos transtornos mentais. 2. Ed. Porto Alegre: Artmed, 2008.

DUBOIS, J. et alii. Dicionário de Linguística. São Paulo: Cultrix, 1973.

FISCHER, Luís Augusto. Contos de Machado: da ética à estética. In: SECCHIN, Antônio Carlos (org.). Machado de Assis, uma revisão. Rio de Janeiro: In-Fólio, 1998.

GENETTE, Gérard. Palimpsestos: a literatura de segunda mão. Tradução de Luciene Guimarães e Maria Antonia Ramos Coutinho. Cadernos do Departamento de Letras Vernáculas, Belo Horizonte: Faculdade de Letras/UFMG, 2006. 
SANTOS, Luciano. O sujeito encarnado: a sensibilidade como paradigma ético em Emmanuel Levinas. Ijuí: Ed. Unijuí, 2009.

SOUZA, Ronaldes de Melo e. O estilo Narrativo de Machado de Assis. In: SECCHIN, Antônio Carlos (Org.). Machado de Assis, uma revisão. Rio de Janeiro: In-Fólio,1998.p. 65-79.

SENNA, Marta de. O olhar oblíquo do bruxo: ensaios machadianos. $2^{\mathrm{a}}$ ed. Rio de Janeiro: língua Geral, 2008.

ZILBERMAN, Regina. Um caso para o leitor pensar. In: FERNANDES, Rinaldo de. $C a$ pitu Mandou Flores: Contos para Machado de Assis nos cem anos de sua morte. São Paulo: Geração Editorial, 2008.

Recebido em: 31/05/2018. Aprovado em: 16/07/2018. 